\title{
Rehabilitation in Parkinson's disease - the challenge to provide early and ongoing, evidence-based, patient-centred care
}

\author{
Reabilitação na doença de Parkinson: mudanças baseadas em evidências \\ para cuidados precoces de pacientes
}

Colleen G. Canning

PhD, Associate Professor, Clinical and Rehabilitation Sciences Research Group, Faculty of Health Sciences, The University of Sydney, Sydney, Australia.

\section{Correspondence:} Colleen G. Canning

The University of Sydney, PO Box 170, Lidcombe NSW 1825, Australia.

E-mail:colleen.canning@sydney. edu.au

Conflict of interest:

There is no conflict of interest to declare.

Received 05 November 2013 Accepted 12 November 2013
$\mathrm{P}$ arkinson's disease is a complex, progressive, multi-system disease associated with motor, cognitive and emotional impairments. On the basis of a review of evidencebased Parkinson's disease guidelines and systematic reviews of non-pharmacological and non-surgical treatments, Domingos and colleagues ${ }^{1}$ offer a timely opinion statement providing physicians with guidelines promoting referral of people with Parkinson's disease to rehabilitation services.

It is clear that the evidence-base for rehabilitation, in particular for physical interventions, ie, physiotherapy and/or exercise ${ }^{2-5}$, is continuing to expand exponentially ${ }^{4,6}$. However, implementing the evidence is challenging, as questions remain regarding optimal modes of physical interventions and optimal dose and intensity of exercise. Domingos and colleagues ${ }^{1}$ (in Figure 1) illustrate the complexities of the available interventions and the potential of some interventions to addresses more than one motor problem. The allied health professionals who deliver rehabilitation interventions are autonomous professionals trained in evidence-based practice and are first-contact practitioners (not requiring a referral from a medical practitioner) in many countries, including Brazil. While it is the responsibility of the physician to facilitate referral, it is the responsibility of rehabilitation professionals to assess the person with Parkinson's disease and to collaboratively with the patient decide upon treatment goals and intervention, based on their evidence-informed judgement. This involves consideration of not only the presenting motor impairments and activity limitations, but also non-motor impairments such as cognitive impairment, disease stage, co-morbidities, as well as exercise history, exercise-self efficacy and individual preferences ${ }^{7,8}$. Although very few serious adverse effects associated with rehabilitation interventions have been reported ${ }^{9}$, the relative risks and benefits of rehabilitation interventions also need to be assessed, particularly with respect to the level of supervision required for physical interventions.

There is a move towards a more collaborative model of healthcare, ie, patient-centred care, where the patient actively participates in making decisions about their individual health care rather than passively accepting the prescription of the health care professional ${ }^{10}$. This model is particularly well-suited to delivering rehabilitation interventions to people with Parkinson's disease, where several interventions are evidence-based, but there is no evidence to indicate which intervention is best. For example, if one of the goals of rehabilitation is to improve aerobic exercise capacity, there is currently supporting evidence for group aerobic exercise $^{11}$, cycle ergometry ${ }^{12,13}$ and treadmill walking ${ }^{12-14}$. Using the patient-centred healthcare model, the individual patient and his/her rehabilitation professionals jointly consider the evidence, the patient's goals and preferences for exercise, as well as pragmatics, such as access to exercise programs, equipment and cost. Additional benefits include the potential to maximize the patient's adherence to the exercise program, collaborative monitoring and modification of the program, as well as development of self-management strategies. The European Physiotherapy Guideline for Parkinson's disease (currently in draft form) provides further information on the implementation of these strategies ${ }^{15}$; incorporating interdisciplinary 
collaboration with key rehabilitation professionals, including Parkinson's disease nurses, occupational therapists and, speech and language therapists.

There will always be a lag between emerging gold-standard evidence from randomised controlled trials and the guidelines and systematic reviews based on this evidence. For example, the recommendations of the European Federation of Neurological Societies and Movement Disorder Society-European Section (EFNS/MDS-ES) review on therapeutic management of Parkinson's disease published in $2013^{16}$ included studies up to the end of 2010. More recently-published randomised controlled trials provide evidence supporting additional modes of physical interventions including Tai-Chi ${ }^{17}$, tango dancing ${ }^{18}$, Irish set dancing ${ }^{19}$, muscle strengthening exercises ${ }^{20}$ and muscle power training ${ }^{21}$. In addition, a multifaceted behavioural change physiotherapy intervention designed to increase physical activity has been shown to have some benefits on physical activity and walking capacity over and above those achieved by traditional physiotherapy ${ }^{22}$. Virtual reality gait training ${ }^{23}$ and occupational therapy ${ }^{24}$ are also currently being tested in large-scale randomised controlled trials.

Despite the exponential evolution of evidence for rehabilitation interventions, significant gaps remain. Motor impairments affecting the upper limbs, and non-motor impairments, such as depression and cognitive impairments are significant contributors to reduced quality of life in people with Parkinson's disease ${ }^{25}$. Therefore, there is an urgent need to explore the potential of rehabilitation interventions designed to address these impairments. There is also a paucity of research focusing on rehabilitation in late Parkinson's disease, particularly in Hoehn and Yahr stage 5 and this knowledge gap needs to be addressed.

The evidence of efficacy of rehabilitation for people with Parkinson's disease has been gained mostly from trials including predominantly early to mid-stage patients. Therefore, the strongest evidence supports the delivery of rehabilitation interventions early in the disease process, when rehabilitation can play a key role in maintaining mobility and preventing secondary impairments of neuromuscular and cardiovascular systems associated with reduced physical activity. Many people with Parkinson's disease, particularly individuals with the Postural Instability Gait Disorder (PIGD) motor phenotype, will present with activity limitations in the early stages, even at their first visit to a neurologist ${ }^{26}$. Despite this, in a recent large survey of 3405 physiotherapists from 17 European countries, a major barrier to delivery of optimal physiotherapy care was that referral to rehabilitation was initiated at too late a stage of disease progression ${ }^{27}$. This finding further highlights the importance of Domingos and colleagues' ${ }^{1}$ opinion statement promoting early referral to rehabilitation. Finally, although there is limited evidence to date, much research activity is currently underway exploring the role of exercise as a potential disease-modifying intervention for people with Parkinson's disease ${ }^{4,5,28,29}$. If exercise is shown to have a disease-modifying effect, this would provide further support for routine referral of people to rehabilitation on diagnosis with Parkinson's disease.

\section{References}

1. Domingos J, Coelho M, Ferreira JJ. Referral to rehabilitation in Parkinson's disease: who, when and to what end? Arq Neuropsiquiatr 2013;71:967-972.

2. Tomlinson CL, Patel S, Meek C, et al. Physiotherapy versus placebo or no intervention in Parkinson's disease. Cochrane Database Syste Rev 2012;7:CD002817.

3. Tomlinson CL, Patel S, Meek C, et al. Physiotherapy intervention in Parkinson's disease: systematic review and meta-analysis. BMJ 2012;345:e5004

4. Rochester L, Nieuwboer A, Lord S. Physiotherapy for Parkinson's disease: defining evidence within a framework for intervention. Neurodegenerat Dis Manag 2011;1:57-65.

5. Earhart GM, Falvo MJ. Parkinson disease and exercise. Compr Physiol 2013;3:833-848.

6. Keus SH, Munneke M, Nijkrake MJ, Kwakkel G, Bloem BR., Physical therapy in Parkinson's disease: evolution and future challenges. Mov Disord 2009;24:1-14.

7. Ellis T, Boudreau JK, DeAngelis TR, et al. Barriers to exercise in people with Parkinson disease. Phys Ther 2013;93:628-636.

8. Ellis T, Cavanaugh JT, Earhart GM, et al. Factors associated with exercise behavior in people with Parkinson disease. Phys Ther 2011;91:1838-1848.
9. Allen NE, Sherrington C, Suriyarachchi GD, Paul SS, Song J, Canning CG. Exercise and motor training in people with Parkinson's disease: a systematic review of participant characteristics, intervention delivery, retention rates, adherence and adverse events in clinical trials. Parkinson Dis 2012:ID854328.

10. van der Eijk M,Nijhuis FA, Faber MJ, Bloem BR. Moving from physiciancentered care towards patient-centered care for Parkinson's disease patients. Parkins Relat Disord 2013;19:923-927.

11. Bridgewater KJ, Sharpe MH. Aerobic exercise and early Parkinson's disease. Neurorehabilitation Neural Repair 1996;10:233-241.

12. Bergen JL, Toole T, Elliot RG $3^{\text {rd }}$, Wallace B, Robinson K, Maitland CG. Aerobic exercise intervention improves aerobic capacity and movement initiation in Parkinson's disease patients. Neuro Rehab 2002;17:161-168.

13. Schenkman M, Hall DA, Barón AE, Schwartz RS, Mettler P, Kohrt WM. Exercise for people in early- or mid-stage Parkinson disease: a 16-month randomized controlled trial. Phys Ther 2012;92:1395-1410.

14. Shulman LM, Katzel LI, Ivey FM, et al. Randomized clinical trial of 3 types of physical exercise for patients with Parkinson's disease. JAMA Neurol 2013;70:183-190.

15. Keus SHJ, Munneke M, Graziano M, et al. European Physiotherapy Guideline for Parkinson's disease (For Review) 2013; available at http:// 
www.parkinsonnet.info/media/11928217/eu_20 physiotherapy_20 guideline_20pd_review_2020131003-1.pdf (accessed 4 November 2013).

16. Ferreira JJ, Katzenschlager R, Bloem BR, et al. Summary of the recommendations of the EFNS/MDS-ES review on therapeutic management of Parkinson's disease. Eur $J$ Neurol 2013;20:5-15.

17. Li F, Harmer P, Fitzgerald K, et al. Tai chi and postural stability in patients with Parkinson's disease. N Engl J Med 2012;366:511-519.

18. Duncan RP, Earhart GM. Randomized controlled trial of communitybased dancing to modify disease progression in Parkinson disease. Neurorehab Neural Repair 2012;26:132-143.

19. Volpe D, Signorini M, Marchetto A, Lynch T, Morris ME. A comparison of Irish set dancing and exercises for people with Parkinson's disease: a phase II feasibility study. BMC Geriatr 2013;13:54.

20. Corcos DM, Robichaud JA, David FJ, et al. A two-year randomized controlled trial of progressive resistance exercise for Parkinson's disease. Mov Disord 2013;28:1230-1240.

21. Paul SS, Canning CG, Song J, Sherrington C, Fung VSC. Leg muscle power is enhanced by training in people with Parkinson's disease: a randomised controlled trial. Clin Rehab 2013; published online 4 November 2013, DOI:10.1177/0269215513507462.
22. van Nimwegen M, Speelman AD, Overeem S, et al. Promotion of physical activity and fitness in sedentary patients with Parkinson's disease: randomised controlled trial. BMJ 2013;346:576.

23. Mirelman A, Rochester L, Reelick M, et al. V-TIME: a treadmill training program augmented by virtual reality to decrease fall risk in older adults: study design of a randomized controlled trial. BMC Neurol 2013;13:15

24. Sturkenboom IH, Graff MJ, Borm GF, et al. Effectiveness of occupational therapy in Parkinson's disease: study protocol for a randomized controlled trial. Trials 2013;14:34.

25. Soh SE, Morris ME, McGinley JL. Determinants of health-related quality of life in Parkinson's disease: a systematic review. Parkins Relat Disord 2011;17:1-9.

26. Hariz GM, Forsgren L. Activities of daily living and quality of life in persons with newly diagnosed Parkinson's disease according to subtype of disease, and in comparison to healthy controls. Acta Neruol Scand 2011;23:20-27.

27. Keus SH. Parkinson's care: insight into physiotherapy within Europe. Neurorehab Neural Repair 2012;26:707-708.

28. Earhart GM, Ellis T, Nieuwboer A, Dibble E. Rehabilitation and Parkinson's disease. Parkinson Dis 2012;2012:371406.

29. Petzinger GM, Fisher BE, McEwen S, Beeler JA, Walsh JP, Jakowec MW Exercise-enhanced neuroplasticity targeting motor and cognitive circuitry in Parkinson's disease. Lancet Neurol 2013;12:716-726. 